\title{
Preprint server seeks way to halt plagiarists
}

Jim Giles, London

An unusual case of plagiarism has struck ArXiv, the popular physics preprint server at Cornell University in Ithaca, New York, resulting in the withdrawal of 22 papers.

In the light of the incident, Cornell physicist Paul Ginsparg, who developed the archive, says that he now intends to investigate measures to prevent such misdemeanours from recurring. In the meantime, Ginsparg is also facing the challenge of potentially libellous material being posted on the server (see below).

The plagiarism case traces its origins to June 2002, when Yasushi Watanabe, a highenergy physicist at the Tokyo Institute of Technology, was contacted by Ramy Naboulsi, who said he was a mathematical physicist. Naboulsi asked for Watanabe's help in obtaining a research position in Japan. Impressed by Naboulsi's work, Watanabe agreed to upload some of his papers to ArXiv, which Naboulsi was unable to do himself as he had no academic affiliation. "I was so amazed at his productivity I began to think he was a genius," Watanabe later wrote in an e-mail to the archive.

By April 2003, Naboulsi had 22 papers on ArXiv, but some of server's users noticed that one of his papers copied parts of the BaBar Physics Book, an online summary of meetings about a high-energy physics experiment at the Stanford Linear Accelerator Center in California. When six more of the papers were shown to be similar to the BaBar book, Watanabe asked for all 22 preprints to be withdrawn. ArXiv labelled the papers as

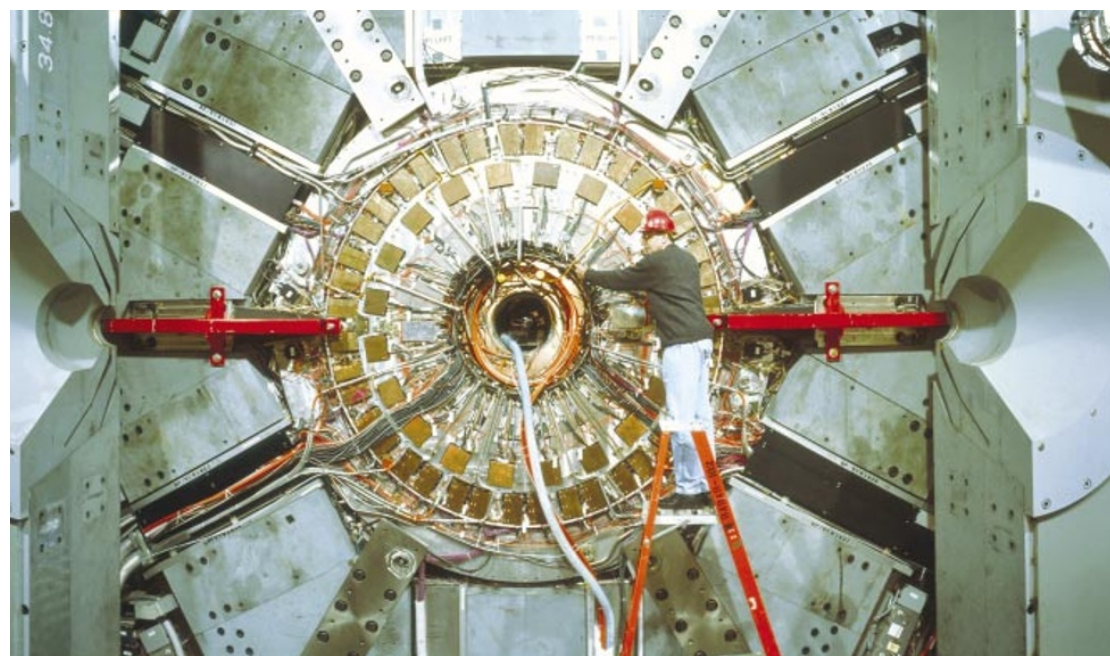

Plundered: experimental results from the BaBar particle detector have been copied by an author.

such but left them on the site, in accordance with its policy.

When contacted by Nature, Naboulsi said that he would like to apologize to ArXiv and to the Stanford centre, but said that his other papers, on cosmology, were not plagiarized.

ArXiv plainly states that "authors must make their own submissions", but Ginsparg is not planning to take any action against Watanabe, who now deeply regrets the incident. "He has already suffered enough over this," says Ginsparg.

Plagiarism is extremely rare on ArXiv only a handful of its 250,000 submissions have been withdrawn for this reason. But the incident has prompted Ginsparg to think about how to prevent further incidents.

He says that his first step will be to take a baseline measure of similarity between the archive's documents, and so generate a warning when a paper that exceeds this threshold is uploaded. Computer software, typically developed for universities to spot student fraud, is available to do this.

"The technology is there," says Fintan Culwin, an expert in anti-plagiarism software at London's South Bank University. "The question is how much does the archive want to pay to have this service." Ginsparg is now looking for a masters or doctoral student to work on the project.

www.arxiv.org

\section{Critical comments threaten to open libel floodgate for physics archive}

\section{A paper criticizing research posted on the} physics preprint server ArXiv has led experts to warn of the potential for future legal actions against the site.

In an article put on the server on 27 October, Alvaro De Rújula, a theoretical physicist at CERN, the European Centre for Particle Physics in Geneva, made a strongly worded attack on Martin Rees, Britain's astronomer royal, and his co-workers.

De Rújula alleged that Rees, who is based at the University of Cambridge, claimed credit for breakthroughs in $\gamma$-ray astronomy while ignoring contributions made by other groups. De Rújula has worked with some of those whom he says were ignored, including Arnon Dar of the Israel Institute of Technology in Haifa.

The incident raises some difficult issues for ArXiv, admit its administrators at Cornell University in Ithaca, New York. Rees was asked by Dar in September to change the citations, and says that he had originally intended to wait until the paper had been peer-reviewed before doing so. But two days after De Rújula's posting, Rees modified his paper to cite Dar's work.

But if the criticism is seen as successful, other authors could rush to pursue similar complaints. "We don't want these food fights

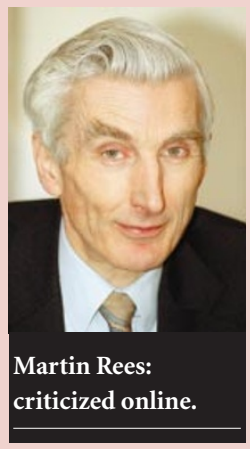
conducted on a regular basis," says Paul Ginsparg, the Cornell physicist who created ArXiv.

The sharp language used by De Rújula to describe Rees could cause further problems for ArXiv - which doesn't usually check papers before they are posted - if De Rújula's paper were deemed libellous in a court of law. And some experts think that it could be. "The accusations against Rees are potentially defamatory," says David Mascord, a media-law specialist at DMC Development, a training company based in Brockenhurst, UK.

Postings on ArXiv are deemed to be published and so are subject to libel law. In the United States, libel actions are hard to pursue because of the right to freedom of speech enshrined in the First Amendment to the constitution.

But because the paper has been published on the web, it is subject to the libel laws of any country in which it can be accessed. Under English law, for example, De Rújula, Ginsparg and Cornell University could all be liable if the De Rújula paper were held to be defamatory.

Ginsparg says that he has not taken legal advice over De Rújula's paper, but that he would remove it if recommended to do so by his lawyers. "ArXiv is just a mindless redistribution system," he adds. "It's not implemented to be a global police force to detect or enforce professional ethics."

Jim Giles 